\title{
Current status and influencing factors of self-management in patients with non-valvular atrial fibrillation under different anticoagulant therapy in Jiangsu province, China: A multi-center across-sectional study
}

\author{
ting Liu \\ First Affiliated Hospital of Soochow University \\ mengxiao Ren \\ School of Nursing, Soochow University \\ lingling Cui \\ School of Nursing, Soochow University \\ bingqing Lu \\ First Affiliated Hospital of Soochow University \\ jie Hui \\ First Affiliated Hospital of Soochow University \\ Omorogieva Ojo \\ University of Greenwich \\ xiaohua Wang ( $\nabla$ sxwang2001@163.com ) \\ First Affiliated Hospital of Soochow University
}

\section{Research Article}

Keywords: Atrial fibrillation, Non-valvular atrial fibrillation, Self-management, Anticoagulant therapy, Influencing factors, China

Posted Date: December 1st, 2020

DOI: https://doi.org/10.21203/rs.3.rs-113956/v1

License: (c) (i) This work is licensed under a Creative Commons Attribution 4.0 International License. Read Full License 


\section{Abstract}

Background: There is little research focusing on the current status and influencing factors of self-management in patients with non-valvular atrial fibrillation (NVAF) under different anticoagulant therapy. This study aims to explore the current status of self-management of NVAF who took Warfarin, New Oral Anticoagulant (NOAC), Aspirin and No medication, and analyze the factors associated with their self-management ability in Jiangsu province, China.

Methods: This was a multi-center, cross-sectional study that was conducted in six hospitals from December 2017 to October 2018. The general information and self-management of patients were collected by questionnaires and from the medical records. Multivariate linear regression analysis was used to identify factors associated with self-management.

Results: A total of 555 participant completed the survey. The status of self-management was unsatisfactory in patients with NVAF, there were significant differences $(P \otimes 0.01)$ of self-management among patients in different anticoagulant groups and Warfarin group was relatively better (71.21 \pm 12.33$)$. Multiple linear regression analysis demonstrated that the determinants of poor self-management in Warfarin group was the lower educational status $(P \otimes 0.01)$; in Aspirin group, comorbidities $(P=0.015)$ and age $₫ 65$ years $(P \otimes 0.01)$ were the determinants of self-poor

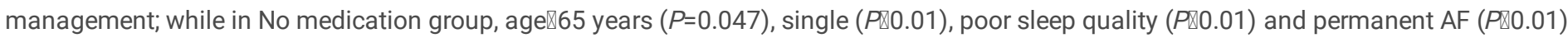
were the determinants of poor self-management.

Conclusion: The current status of self-management among Chinese patients

with NVAF in Jiangsu province does not appear optimistic. Therefore, further studies should focus on how to improve the self-management among NVAF patients. In addition, policy makers should pay attention to identify patients at risk of poor self-management and take measures to improve their self-management.

\section{Background}

Atrial fibrillation (AF) is a serious cardiovascular health problem and it is the most common form of cardiac arrhythmia, it has been reported that the prevalence of $\mathrm{AF}$ in the elderly Chinese population was $1.8 \%[1]$. Research suggest a rising prevalence and incidence of $\mathrm{AF}$ as a consequence of the aging populations[2]. It was predicted that there would be 5.2 million men and 3.1 million women aged $>60$ years with $\mathrm{AF}$ in China by 2050[3]. AF is associated with an increased risk of stroke and deaths[4], and most patients with AF are at risk of developing thromboembolic events[5]. Therefore, the use of anticoagulant therapy are the cornerstone of integrated management of AF. For stroke prevention, there is evidence that warfarin can reduce stroke risk by $60 \%[6]$, while New Oral Anticoagulant (NOAC) are being used more frequently because of their ease of administration and comparative efficacy in reducing thromboembolism and major bleeding[7]. In addition, approximately $30 \%$ of AF patients are associated with coronary artery disease (CAD) who underwent the percutaneous coronary intervention (PCl) with stenting and need took anti-platelet therapy with aspirin[8]. GARFIELD study Chinese subgroup data indicated that nearly one fifth of the patients with middle and high-risk NVAF did not receive any anticoagulant therapy in China due to fear of bleeding, costs of agents and dosing convenience[9].

Recent guidelines for AF management propose that patients should be involved as partners in their management of $\mathrm{AF}$ and this has been recognized as an essential practice[10]. The European Heart Rhythm Association and Heart Rhythm Society have also emphasized the need for effective self-management of $A F[10,11]$, as this can reduce the burden of AF[12] and has the potential to mitigate AF-related adverse events[11]. Several meta-analyses have reported that self-management can significantly reduce thromboembolic events and all-cause mortality[13-15]. In summary, the ability of self-management in patients with AF is of great significance in the development and prognosis of the disease. Therefore, promoting self-management practices should be a clinical priority. However, studies about self-management of AF were only focuses on monitoring embolism and bleeding in patients who took warfarin[16,17]. In China, Wang et al[18] investigated the self-management ability of AF patients who took warfarin and found the self-management ability of AF patients was poor. Based on the development of The selfmanagement scales for AF patients by our research team, we have conducted a preliminary survey of AF patients who took warfarin in 2018 and found that the level of their self-management was unsatisfactory[19]. Yet, there is little research focusing on the status of self-management in AF patients who taking NOAC, Aspirin and No anticoagulants. This study aims to explore the current status of self-management of NVAF who took Warfarin, NOAC, Aspirin and No medication, and analyze the factors associated with their self-management ability in Jiangsu province, China.

\section{Methods}

\section{The aim, design and setting of the study}


The aim of this multi-center, cross-sectional study was to explore the currents status and influencing factors of self-management in patients with NVAF under different anticoagulant therapy among Chinese patients with NVAF in Jiangsu province. The study complied with the Helsinki Declaration and ethical approval for the study was obtained from the local ethical committee and all patients provided an informed consent.

A purposive sampling method was used to recruit hospitalized patients in the different areas of Jiangsu province with NVAF from six hospitals from December 2017 to October 2018. Inclusion criteria were as follows: patients were (1)age $\geq 18$ years; (2)AF by electrocardiogram or ambulatory electrocardiogram recorder according to the guideline of the European Society of Cardiology (ESC)[1]; (3)had volunteered to participate in this study, and willing to provide informed consent. Exclusion criteria were as follows: (1)AF caused by reversible factors, eg: cardiac surgery, uncontrolled hyperthyroidism[20]; (2)valvular AF; (3)malignant tumors and blood diseases[16]; (4)underwent surgeries within three months.

\section{General information questionnaire}

General information questionnaire including demographic and clinical data. Demographic data including age (years), gender, education status, payment, marital status, dwelling status, quality of life (QoL). Clinical data including body mass index (BMI, BMI grouping according to Chinese standards), clinical diagnosis, duration, type of $\mathrm{AF}$, severity of symptom, current drug type, $\mathrm{CHA}_{2} \mathrm{DS}_{2}-\mathrm{VASC}$ score, comorbidities, whether they received radio frequency ablation or re-admission within 6 month and sleep quality. The sleep quality was evaluated by the Visual analog scale (VAS), VAS score < 3 indicated good sleep quality; 4-6 indicated average sleep quality; 7-10 indicated poor sleep quality[21].

\section{The self-management scales for AF patients}

The scales were developed by Lu et al in 2017[22]. Scale 1, 2 and 3 were used to evaluate the self-management in patients without any anticoagulants, taking NOAC or Aspirin group and Warfarin group, respectively. The Cronbach's a of three scales were $0.732,0.732$ and 0.845 and the cumulative variation rate (\%) were $61.90 \%, 63.09 \%$ and $66.11 \%$, respectively, which suggests that the self-management scales have good reliability and validity. Scale 1 included three dimensions, namely: (1)adverse hobbies, (2)daily routine and exercise, (3)monitoring the symptoms of embolism and AF. Scale 2 included 4 dimensions, which added a dimension of monitoring the symptoms of bleeding on the basis of Scale 1. Scale 3 included 5 dimensions, which added a dimension of warfarin-specific management on the basis of Scale 2. The Likert 4grade scoring system (always, often, sometimes, never) was used for all response items in the scales with a forward score of 0-3 and a reverse score which is the opposite. All the scores of the three scales were converted into percentage system. The higher the score was, the better the self-management of AF patients was. The self-management scales for AF patients were presented in the supplementary materials.

\section{Chinese Version of Atrial Fibrillation Quality of Life Assessment Tool}

In 2016, Zhang[23] localized the Heart-Related Quality (HRQoL) questionnaire of Spertus J to (AF-QoL-18) for AF patients. The Cronbach's a of the localized AF-QoL scale (AF-QoL-18) was 0.915, which indicated the tool had good reliability. The scale has 17 items, including 3 dimensions of physical, psychological and sex life. The Likert 5-grade scoring system (strongly agree, agree, neither agree nor disagree, disagree and strongly disagree) was used for the response items in the scale, with a total score of 17-85. Before data processing, the score was converted into a percentage system (actual score $85^{\natural} 100$ ), the higher the score, the higher the quality of life.

\section{The CHA2DS2VASc score[24]}

The CHA2DS2-VASc score was calculated for each patient to categorize the risk of stroke by assigning 1 point each for age between 65 and 74 years, a history of hypertension, diabetes mellitus, congestive heart failure, vascular disease (CAD or peripheral artery disease), female sex and 2 points each for a history of stroke/TIA/

thromboembolism and age $\geq 75$ years. The total possible score was 9 points and higher scores indicated a higher risk of stroke. According to the 2016 ESC guideline, the high risk of stroke is CHA2DS2VASc $\geq 2$ for males and CHA2DS2VASc $\geq 3$ for female.

\section{Data collection}

The members of the research team received unified training. Prior to the investigation, the researcher explained the purpose and significance of the study in detail to the patients and made clear that the patients' privacy will be protected. Patients were asked to sign the informed consent. The questionnaires were issued with unified language guidance to ensure the homogeneity of the investigation. The questionnaires were completed by patients themselves after stating the purpose of the survey. The content of the demographic data were completed by patients themselves and clinical data were obtained from the medical records. For some patients with low education level and impaired vision, the researchers simply and clearly read the questions/item, and the patients made the choice. All questionnaires were collected on the spot and checked whether there were omissions or non-conformance in the questionnaires. If errors were present, the data were completed or modified in 
time to ensure the accuracy of the information. Due to the difference in understanding the ability and education level of the patients, it took 1530 minutes to complete the questionnaires.

\section{Statistical analysis}

The SPSS25.0 statistics analysis package was used to conduct the descriptive statistics. Continuous variables were reported as means \pm standard deviation (SD) and categorical variables as numbers and percentages. One-way ANOVA was used for mean comparison between multiple groups. The multivariate linear regression analysis was used to analyze the determinants of self-management and $P<0.05$ was considered statistically significant.

\section{Results}

A total of 603 questionnaires were administered, 555 participants completed the survey (the response rate of valid questionnaires was $92 \%$ ). Forty-eight questionnaires were discarded because they were not collected on the spot and fully completed. There were no substantial differences in demographic characteristics between the 555 subjects who completed the questionnaire and the 48 subjects who did not (data not shown). The participants were predominantly married (97.3\%), most were aged 65 years or more (77.5\%) and with a low level (illiteracy, primary and junior secondary) of education (77.3\%). A large proportion of participants (40.4\%) had a history of NVAF for 5 years or more. The vast majority ( $82.3 \%$ ) had at least one comorbid condition. A total of 448 patients had a CHA2DS2-VASC score $\geq 2$. Only $6 \%$ ( $n=43$ ) of the sample had received radio frequency ablation and $44.7 \%$ had re-admission within 6 month. Demographic and clinical data of the participants are shown in Table 1.

According to different anticoagulant therapy they took, patients were divided into four groups: Warfarin group (25\%, $\mathrm{n}=136)$, NOAC group (6\%, $\mathrm{n}=32)$, Aspirin group $(31 \%, \mathrm{n}=171)$, No medication group $(38 \%, \mathrm{n}=216)$. The status of self-management was unsatisfactory in patients with NVAF in this study. There were significant differences $(P \otimes 0.01)$ in the scores of self-management among NVAF patients among different groups. Warfarin group had relatively better $(71.21 \pm 12.33)$ self-management ability. Compared with Warfarin group, the self-management ability of NOAC group (69.59 \pm 13.37 ) and Aspirin group (69.03 \pm 12.20$)$ were unsatisfactory, while No medication group had the worst level of selfmanagement $(66.12 \pm 11.36)$. The dimension of "monitoring the symptom of embolism and AF" had the lowest score in all groups. The scores of all dimensions of self-management in NVAF patients are shown in Table 2.

The results of one-way ANOVA analyses are shown in Table 3. In the Warfarin group, the variables that correlated with self-management were educational status ( $P \otimes 0.01)$, severity of symptom ( $P \bigotimes 0.01)$, and CHA2DS2-VASC score (Pख0.05). There were no significant factors which correlated with self-management in the NOAC group. Age $(P \otimes 0.01)$ and comorbidities $(P \otimes 0.01)$ were correlated with self-management in Aspirin group. Marital status ( $P \otimes 0.01)$, educational status (Pख0.05), sleep quality (Pख0.01), type of AF (Pख0.01), QoL (Pख0.05) and re-admission within 6 month $(P \otimes 0.01)$ were correlated with self-management of No medication group.

The independent variables associated with self-management which were $P \otimes 0.1$ in the one-way ANOVA were included in the multivariable linear regression. In addition, age, severity of symptoms and educational status were included in the multivariable linear regression. Since the sample size of NOAC group was too small to satisfy the condition of multivariable linear regression, so the results of multivariable linear regression of NOAC group were not given. Multiple linear regression analysis indicated that the model explained $12.3 \%, 25.9 \%$ and $10.1 \%$ of the variance in self-management in Warfarin, Aspirin and No medication groups, respectively. The results showed that the poorer self-management in Warfarin group was associated with "low education status" ( $P \otimes 0.01)$; poorer self-management in Aspirin group was associated with "age $₫ 65$ years" ( $P]$ $0.01)$ and "having comorbidities" ( $P \otimes 0.05)$; poorer self-management in No medication group was associated with "age 865 years" (Pख0.05), "single" ( $P \otimes 0.01)$, "poorer sleep quality" (Pख0.01) and "with permanent AF" $(P \otimes 0.01)$. Influence factors of self-management ability of three groups are shown in Table 4.

\section{Discussion}

The result of this study showed that the self-management of NVAF patients in Jiangsu province, China was unsatisfactory, especially in the dimension of "monitoring symptom of embolism and AF", this is consistent with the result of McCabe PJ et al[25]. Meanwhile, our study also found that there were significant differences in the self-management of NVAF patients among the four groups with different anticoagulant therapy, of which the Warfarin group had the better self-management ability, while the No medication group was the poorest. The reason might be warfarin is the most commonly used oral anticoagulant in clinical practice to reduce the risk of ischemic stroke in patients with AF, due to its narrow treatment window and long half-life, it is susceptible to influencing of other drugs or foods, so doctors provided relatively more health education to patients who took warfarin in order to help them monitored coagulating function regularly and adjust the dosage according to the examination results[26], which may be helpful to improve the patient's self-management ability[27]. Although AF patients without medication had low level of self-management, the score of the dimension in "monitoring the symptoms of embolism and AF" was the highest which indicated this group of patients paid more attention to occurrence of embolic events due to no anticoagulants therapy[28,29].

Page 4/13 


\section{Educational status and age}

Educational status significantly influenced the choice of appropriate therapies, such as choice warfarin and NOAC administration for AF in order to prevent embolic events[30]. Our survey showed that low education level was the only independent risk factor affecting the selfmanagement ability of patients in Warfarin group. Better-educated patients are more capable of receiving and handling information about AF. The KAP (Knowledge, attitude, practice) model mentions that "knowledge" is the basis behavior[31], and the lack of knowledge or misunderstanding may be the primary reasons for poor self-management behavior. ${ }^{32} \mathrm{It}$ is possible that the patients with a lower educational background had a misconception due to insufficient knowledge of the disease, which could have hindered the implementation of selfmanagement behavior.

Several studies indicated that elderly patients exhibit better self-management behavior than younger patients[33-35]. In our study, old age also was a protective factor of self-management in Aspirin and No medication groups. Elderly patients have relatively sufficient time to focus on the self-management, while younger patients who are so engaged in their careers or busy with social interactions that had less to manage their disease regularly[34]. Therefore, it is important that professionals should guide younger patients to pay more attention to their conditions.

\section{Sleep quality and Family support}

Higher sleep efficiency was significantly associated with a lower likelihood of AF[36]. Several studies demonstrate that there is an association between abnormal total sleep time and AF[37,38]. Meanwhile, the poor sleep quality imposes limitations in the implementation of selfmanagement behavior[39]. Our study indicated that poor sleep quality is the most important independent risk factor affecting the participants' self-management in No medication group. Poor sleep quality was closely associated with daytime dysfunction, such as fatigue, depression, anxiety, pain, excessive daytime sleepiness, and decrements in functional performance[40], which may lead to patient inability to efficiently implement self-management behavior.

Family support, especially spouse support, plays an important role in the implementation of patients' self-management behavior[41]. Compared to single individuals, married individuals are better at self-management behaviors owing to the care of their spouses[42], which is consistent with the findings of this study that marriage was a protective factor that promotes the self-management of patients with AF in No medication group.

\section{Comorbidities and severity of disease}

Except for lone AF, most AF are secondary to other diseases (such as: arterial hypertension, heart failure, valvular heart disease, hyperthyroidosis)[43], so the management and treatment programs of AF are relatively complex. It is not surprising that comorbidities were an independent risk factor for poor self-management in Aspirin group, which is consistent with previous study by Ausili et al[44,45]. A possible reason is that patients who had comorbid conditions were less confident when making self-management decisions since they had to simultaneously consider two or more conditions, which increases the complexity of disease management[46].

In addition, severity of disease can be used as a predictor of patients' self-management ability[47]. In this study, paroxysmal AF patients may be more likely to engage in their self-management than those who are permanent AF and persistent patients. The reason may be serious symptoms of permanent and persisten AF patients could make them more likely to perceive themselves as "badly ill", which could lead to a passive attitude and consequently perform worse self-management[48].

\section{Conclusions}

The result of our study indicated that self-management was unsatisfactory in patients with NVAF in Jiangsu province, China. Compared to Warfarin group, the self-management of NOAC group, Aspirin group were more unsatisfactory, and the No medication group which had the worst level of self-management. Poor self-management level associated with low educational level, age 65 , poor sleep quality, single and persistent AF. These findings can help professionals identify patients at high risk of poor self-management, take effective interventions to improve self-management behavior of NVAF patients.

\section{Abbreviations}

AF: Atrial fibrillation; NVAF: Non-valvular atrial fibrillation; NOAC: New Oral Anticoagulant; CAD: coronary artery disease; PCl: percutaneous coronary intervention ; ESC: European Society of Cardiology ; CHA2DS2-VASc: Congestive heart failure, hypertension, age $\geq 75$ (doubled), diabetes, stroke (doubled), vascular disease, age 65-74, and sex (female); QoL: quality of life; VAS: Visual analog scale; KAP: Knowledge, attitude, practice[ 


\section{Declarations}

\section{Ethics approval and consent to participate}

The study was approved by the ethics committee of the first affiliated hospital of Soochow University (Ethical number: 2017029) and written informed consent was obtained from each participant.

\section{Consent for publication}

Not applicable

\section{Availability of data and materials}

The datasets used and analyzed during the current study are available from the corresponding author on reasonable request.

\section{Competing interests}

The authors declare that they have no competing interests.

\section{Funding}

No funding was received for this study.

\section{Authors' contributions}

Ting liu and Mengxiao Ren: Data Collection, interpretation of data, manuscript writing; Lingling Cui: Interpretation of data, revision of the manuscript; Bingqing Lu, Jie Hui: Data collection, interpretation of data; Omorogieva Ojo: revision of the manuscript; Xiao-hua Wang: Project development, revision of the manuscript, approval of the final version. All authors agree with the authors list appeared on the manuscript.

\section{Acknowledges}

Not applicable

\section{References}

1. Li LH, Sheng CS, Hu BC, et al. The prevalence, incidence, management and risks of atrial fibrillation in an elderly Chinese population: a prospective study.BMC Cardiovasc Disord. 2015;15:31. Published 2015 May 8.

2. Heeringa J, van der Kuip DA, Hofman A, et al. Prevalence, incidence and lifetime risk of atrial fibrillation: the Rotterdam study. Eur Heart J. 2006;27(8):949-953.

3. Chiang CE, Wang KL, Lip GY. Stroke prevention in atrial fibrillation: an Asian perspective. Thromb Haemost. 2014;111(5):789-797.

4. Dalen JE, Alpert JS. Silent Atrial Fibrillation and Cryptogenic Strokes. Am J Med. 2017;130(3):264-267.

5. Ruddox V, Sandven I, Munkhaugen J, Skattebu J, Edvardsen T, Otterstad JE. Atrial fibrillation and the risk for myocardial infarction, allcause mortality and heart failure: A systematic review and meta-analysis. Eur J Prev Cardiol. 2017;24(14):1555-1566.

6. Hart RG, Benavente O, McBride R, Pearce LA. Antithrombotic therapy to prevent stroke in patients with atrial fibrillation: a metaanalysis. Ann Intern Med. 1999;131(7):492-501.

7. Chang SH, Chou IJ, Yeh YH, et al. Association Between Use of Non-Vitamin K Oral Anticoagulants With and Without Concurrent Medications and Risk of Major Bleeding in Nonvalvular Atrial Fibrillation. JAMA. 2017;318(13):1250-1259.

8. Lip GY, Laroche C, Dan GA, et al. A prospective survey in European Society of Cardiology member countries of atrial fibrillation management: baseline results of EURObservational Research Programme Atrial Fibrillation (EORP-AF) Pilot General Registry [published correction appears in Europace. 2014 Jun;16(6):941]. Europace. 2014;16(3):308-319.

9. Sun Y, Hu D; Chinese Investigators of GARFIELD; Chinese Investigators of GARFIELD. Zhonghua Xin Xue Guan Bing Za Zhi. 2014;42(10):846-850.

10. Kirchhof P, Benussi S, Kotecha D, et al. 2016 ESC Guidelines for the management of atrial fibrillation developed in collaboration with EACTS. Eur Heart J. 2016;37(38):2893-2962.

11. Lane DA, Aguinaga L, Blomström-Lundqvist C, et al. Cardiac tachyarrhythmias and patient values and preferences for their management: the European Heart Rhythm Association (EHRA) consensus document endorsed by the Heart Rhythm Society (HRS), Asia Pacific Heart Rhythm Society (APHRS), and Sociedad Latinoamericana de Estimulación Cardíaca y Electrofisiología (SOLEACE). Europace. 2015;17(12):1747-1769. 
12. Griffin JM, Stuart-Mullen LG, Schmidt MM, et al. Preparation for and Implementation of Shared Medical Appointments to Improve SelfManagement, Knowledge, and Care Quality Among Patients With Atrial Fibrillation. Mayo Clin Proc Innov Qual Outcomes. 2018;2(3):218225. Published 2018 Jul 27.

13. Christensen TD, Johnsen SP, Hjortdal VE, Hasenkam JM. Self-management of oral anticoagulant therapy: a systematic review and metaanalysis. Int J Cardiol. 2007;118(1):54-61.

14. Heneghan C, Ward A, Perera R, et al. Self-monitoring of oral anticoagulation: systematic review and meta-analysis of individual patient data [published correction appears in Lancet. 2012 Mar 24;379(9821):1102]. Lancet. 2012;379(9813):322-334.

15. Heneghan CJ, Spencer EA, Mahtani KR. Cochrane corner: self-monitoring and self-management of oral anticoagulation. Heart. 2017;103(12):895-896.

16. Grunau BE, Wiens MO, Harder KK. Patient self-management of warfarin therapy: pragmatic feasibility study in Canadian primary care. Can Fam Physician. 2011;57(8):e292-e298.

17. Pugh AN, Murphy BL. Self-testing and self-management of warfarin anticoagulation therapy in geriatric patients. Consult Pharm. 2013;28(5):319-321.

18. Wang GN, Cui Y, Yang FG et al. [Study on self-management of warfarin therapy in patients with atrial fibrillation: the influencing factors]. Journal of Nursing Science. 2019;34(11), 5-8.

19. LU Bingqing, Tong Shuping, Hui Jie et al. Development and psychometric testing of the Self-management Scale for Atrial Fibrillation patients treated with warfarin. Chinese Nursing Management. 2018. 18(6): p. 761-765.

20. Gao P, Fang Q, Wang JL, Fan JBet al. [Causes of insufficient anticoagulation in Chinese patients with non-valvlar atrial fibrillation]. Zhonghua Xin Xue Guan Bing Za Zhi. 2013; 41(11), 931-934.

21. Zisapel N, Nir T. Determination of the minimal clinically significant difference on a patient visual analog sleep quality scale. J Sleep Res. 2003 Dec;12(4):291-8.

22. LU Bingqing, Tong Shuping, Hui Jie et al. Development and psychometric testing of the Self-management Scale for Atrial Fibrillation patients treated with warfarin. Chinese Nursing Management. 2018. 18(6): p. 761-765.

23. Zhang Chenglin, Yang Xiaofang, Lu Bingqing et al. Reliability and validity of Chinese version of Atrial Fibrillation- Quality of Life- 18 . Chin J Prac Nurs. 2017;33(9): 1441-1445.

24. Lip GY, Nieuwlaat R, Pisters R, Lane DA, Crijns HJ. Refining clinical risk stratification for predicting stroke and thromboembolism in atrial fibrillation using a novel risk factor-based approach: the euro heart survey on atrial fibrillation. Chest. 2010;137(2):263-272.

25. McCabe PJ, Schad S, Hampton A, Holland DE. Knowledge and self-management behaviors of patients with recently detected atrial fibrillation. Heart Lung. 2008;37(2):79-90.

26. Ruff CT, Giugliano RP, Braunwald E, et al. Comparison of the efficacy and safety of new oral anticoagulants with warfarin in patients with atrial fibrillation: a meta-analysis of randomised trials. Lancet. 2014;383(9921):955-962.

27. de Souza TF, Colet CF, Heineck I. Knowledge and information levels and adherence to oral anticoagulant therapy with warfarin in patients attending primary health care services. J Vasc Bras. 2018;17(2):109-116.

28. Diener HC, Eikelboom J, Connolly SJ, et al. Apixaban versus aspirin in patients with atrial fibrillation and previous stroke or transient ischaemic attack: a predefined subgroup analysis from AVERROES, a randomised trial. Lancet Neurol. 2012;11(3):225-231.

29. Joseph N, Chiranjeevi M, Sen S, Singh P, Saini M, Beg S. Awareness on Hypertension and its Self-Management Practices Among Hypertensive Patients Attending Outreach Clinics of a Medical College in South India. Kathmandu Univ Med J (KUMJ). 2016;14(55):202209.

30. Hernández Madrid A, Potpara TS, Dagres N, et al. Differences in attitude, education, and knowledge about oral anticoagulation therapy among patients with atrial fibrillation in Europe: result of a self-assessment patient survey conducted by the European Heart Rhythm Association. Europace. 2016;18(3):463-467.

31. Hamilton NE, Belzer EG, Thiebaux HJ. An experimental evaluation of the KAP model for HE. Int J Health Educ. 1980;23(3):156-161.

32. Lorig KR, Sobel DS, Ritter PL, Laurent D, Hobbs M. Effect of a self-management program on patients with chronic disease. Eff Clin Pract. 2001 Nov-Dec;4(6):256-62.

33. Huang M, Zhao R, Li S, Jiang X. Self-management behavior in patients with type 2 diabetes: a cross-sectional survey in western urban China. PLoS One. 2014;9(4):e95138. Published 2014 Apr 17.

34. Weijman I, Ros WJ, Rutten GE, Schaufeli WB, Schabracq MJ, Winnubst JA. The role of work-related and personal factors in diabetes selfmanagement. Patient Educ Couns. 2005 Oct;59(1):87-96.

35. Rockwell JM, Riegel B. Predictors of self-care in persons with heart failure. Heart Lung. 2001;30(1):18-25. 
36. Kwon Y, Gharib SA, Biggs ML, et al. Association of sleep characteristics with atrial fibrillation: the Multi-Ethnic Study of Atherosclerosis. Thorax. 2015;70(9):873-879.

37. Khawaja O, Sarwar A, Albert CM, Gaziano JM, Djoussé L. Sleep duration and risk of atrial fibrillation (from the Physicians' Health Study). Am J Cardiol. 2013;111(4):547-551.

38. Han X, Yang Y, Chen Y, et al. Association between insomnia and atrial fibrillation in a Chinese population: A cross-sectional study. Clin Cardiol. 2017;40(9):765-769.

39. Chasens ER, Korytkowski M, Sereika SM, Burke LE. Effect of poor sleep quality and excessive daytime sleepiness on factors associated with diabetes self-management. Diabetes Educ. 2013;39(1):74-82.

40. Killgore WD, Balkin TJ, Wesensten NJ. Impaired decision making following 49 h of sleep deprivation. J Sleep Res. 2006 Mar;15(1):7-13.

41. Gallant MP. The influence of social support on chronic illness self-management: a review and directions for research. Health Educ Behav. 2003;30(2):170-195.

42. Ni H, Nauman D, Burgess D, Wise K, Crispell K, Hershberger RE. Factors influencing knowledge of and adherence to self-care among patients with heart failure. Arch Intern Med. 1999;159(14):1613-1619.

43. Potpara TS, Lip GY. Lone atrial fibrillation: what is known and what is to come. Int J Clin Pract. 2011;65(4):446-457.

44. Ausili D, Rebora P, Di Mauro S, et al. Clinical and socio-demographic determinants of self-care behaviours in patients with heart failure and diabetes mellitus: A multicentre cross-sectional study. Int J Nurs Stud. 2016;63:18-27.

45. Ausili D, Rossi E, Rebora P, et al. Socio-demographic and clinical determinants of self-care in adults with type 2 diabetes: a multicentre observational study. Acta Diabetol. 2018;55(7):691-702.

46. Ausili D, Rebora P, Di Mauro S, et al. Clinical and socio-demographic determinants of self-care behaviours in patients with heart failure and diabetes mellitus: A multicentre cross-sectional study. Int J Nurs Stud. 2016;63:18-27.

47. Rockwell JM, Riegel B. Predictors of self-care in persons with heart failure. Heart Lung. 2001;30(1):18-25.

48. Horsburgh ME. Self-care of well adult Canadians and adult Canadians with end stage renal disease. Int J Nurs Stud. 1999 Dec;36(6):44353.

\section{Tables}

Table1 Demographic and clinical characteristics in patients with NVAF 


\begin{tabular}{|c|c|c|}
\hline Variables & Classification & $N(\%)$ \\
\hline \multicolumn{3}{|l|}{ Demographic data } \\
\hline Gender & Male & $296(53.3)$ \\
\hline Age (years) & $\nabla 65$ & $125(22.5)$ \\
\hline Marital status & Married & $540(97.30)$ \\
\hline \multirow[t]{3}{*}{ Educational status } & Illiteracy & $153(27.6)$ \\
\hline & Primary and junior secondary & $276(49.7)$ \\
\hline & Senior high school and above & $126(22.7)$ \\
\hline \multirow[t]{2}{*}{ Dwelling status } & Live alone & $44(7.9)$ \\
\hline & Other & $511(92.1)$ \\
\hline \multirow[t]{2}{*}{ Payment } & Medical insurance & $427(76.9)$ \\
\hline & Self-paying & $128(23.1)$ \\
\hline \multirow[t]{2}{*}{ QoL } & High & $471(84.8)$ \\
\hline & Low & $84(15.2)$ \\
\hline \multicolumn{3}{|l|}{ Clinical data } \\
\hline \multirow[t]{4}{*}{ BMI $\left(\mathrm{kg} / \mathrm{m}^{2}\right)$} & $\otimes 18.5$ & $32(7.3)$ \\
\hline & $18.5 \sim 23.9$ & $267(43.2)$ \\
\hline & $24 \sim 27.9$ & $200(39.0)$ \\
\hline & $\geq 28$ & $56(10.4)$ \\
\hline \multirow[t]{3}{*}{ Sleep quality } & Good & $45(8.1)$ \\
\hline & Average & $259(46.7)$ \\
\hline & Poor & $251(45.2)$ \\
\hline \multirow[t]{4}{*}{ Severity of symptom } & Asymptomatic & $60(10.8)$ \\
\hline & Mild & $320(57.7)$ \\
\hline & Moderate & $151(27.2)$ \\
\hline & Severe & $24(4.3)$ \\
\hline \multirow[t]{3}{*}{ Type of AF } & Paroxymal & $365(65.8)$ \\
\hline & Persistent & $155(27.9)$ \\
\hline & Permanent & $35(6.3)$ \\
\hline \multirow[t]{3}{*}{ Comorbidities } & 0 & $98(17.7)$ \\
\hline & 1 & $167(30.1)$ \\
\hline & $\geq 2$ & $290(52.2)$ \\
\hline \multirow[t]{3}{*}{ Current drug types } & 0 & $37(6.6)$ \\
\hline & $1-4$ & $426(76.8)$ \\
\hline & $\geq 5$ & $92(16.6)$ \\
\hline \multirow[t]{3}{*}{$\mathrm{CHA}_{2} \mathrm{DS}_{2}$-VASC score } & 0 & $32(5.8)$ \\
\hline & 1 & $75(13.5)$ \\
\hline & $\geq 2$ & $448(80.7)$ \\
\hline Course of disease (years) & $<1$ & $116(20.9)$ \\
\hline
\end{tabular}

Page 9/13 


\begin{tabular}{|lll|} 
& $1-5$ & $215(38.7)$ \\
\hline Radio frequency ablation & Yes & $224(40.4)$ \\
Re-admission $(6 \mathrm{~m})$ & Yes & $43(7.4)$ \\
\hline
\end{tabular}

NVAF: non-valvular atrial fibrillation; AF:atrial fibrillation; BMI: Body Mass Index; QoL: quality of life; 6 m: 6 month.

Table 2 Comparison of the scores of self-management in patients with NVAF with different anticoagulant therapy

\begin{tabular}{|c|c|c|c|c|c|c|}
\hline & Warfarin & NOAC & Aspirin & No medication & $\mathrm{F} / \mathrm{t}$ & $P$ \\
\hline Total scores of self-management & $71.21 \pm 12.33$ & $69.59 \pm 13.37$ & $69.03 \pm 12.20$ & $66.12 \pm 11.36$ & 5.366 & $\varangle 0.01^{\square}$ \\
\hline Adverse hobbies & $88.65 \pm 16.06$ & $86.98 \pm 17.19$ & $88.30 \pm 16.33$ & $90.90 \pm 14.36$ & 1.300 & 0.273 \\
\hline Daily routine and exercise & $73.35 \pm 20.12$ & $79.69 \pm 19.51$ & $73.90 \pm 17.09$ & $75.06 \pm 19.26$ & 1.096 & 0.350 \\
\hline Monitoring the symptoms of embolism and $\mathrm{AF}$ & $56.96 \pm 17.61$ & $53.13 \pm 19.29$ & $51.49 \pm 17.93$ & $61.94 \pm 19.65$ & 10.516 & $\nabla 0.01^{\square}$ \\
\hline Monitoring the symptoms of bleeding & $76.72 \pm 21.43$ & $72.92 \pm 25.49$ & $75.73 \pm 21.50$ & - & 0.307 & 0.673 \\
\hline Warfarin-specific management & $74.31 \pm 21.43$ & - & - & - & - & - \\
\hline
\end{tabular}

NVAF: non-valvular atrial fibrillation; NOAC: new oral anticoagulant; -: blank; ${ }^{\square}: P \otimes 0.01$

Table 3 Comparisons of the scores of self-management in NVAF patients with different anticoagulant therapy at different demographic and clinical characteristics 


\begin{tabular}{|c|c|c|c|c|c|c|c|c|c|}
\hline \multirow[t]{3}{*}{ Variables } & \multirow[t]{3}{*}{ Classification } & \multicolumn{2}{|l|}{ Warfarin } & \multicolumn{2}{|l|}{ NOAC } & \multicolumn{2}{|l|}{ Aspirin } & \multicolumn{2}{|c|}{ No medication } \\
\hline & & $\begin{array}{l}\text { Scores of } \\
\text { self } \\
\text { management }\end{array}$ & $\mathrm{F}$ & $\begin{array}{l}\text { Scores of } \\
\text { self } \\
\text { management }\end{array}$ & $\mathrm{F}$ & $\begin{array}{l}\text { Scores of } \\
\text { self } \\
\text { management }\end{array}$ & $\mathrm{F}$ & $\begin{array}{l}\text { Scores of } \\
\text { self } \\
\text { management }\end{array}$ & $\mathrm{F}$ \\
\hline & & 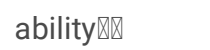 & & ability欧 & & ability欧 & & ability欧 & \\
\hline \multirow[t]{2}{*}{ Gender } & Male & $70.41 \pm 12.46$ & 0.792 & $66.40 \pm 13.39$ & 2.827 & $68.71 \pm 14.48$ & 0.125 & $65.25 \pm 12.34$ & 1.319 \\
\hline & Female & $72.32 \pm 12.17$ & & $74.26 \pm 12.38$ & & $69.37 \pm 9.28$ & & $67.02 \pm 10.22$ & \\
\hline \multirow[t]{2}{*}{ Age (years) } & $\nabla 65$ & $68.34 \pm 11.75$ & 2.010 & $65.19 \pm 11.70$ & 1.605 & $20.39 \pm 11.48$ & $9.301^{\square}$ & $63.74 \pm 11.31$ & 3.021 \\
\hline & $\geq 65$ & $71.99 \pm 12.42$ & & $71.59 \pm 13.85$ & & $63.34 \pm 13.62$ & & $66.87 \pm 11.30$ & \\
\hline \multirow[t]{4}{*}{ BMI $\left(\mathrm{kg} / \mathrm{m}^{2}\right)$} & $<18.5$ & $73.61 \pm 9.12$ & 0.281 & - & & $66.88 \pm 7.68$ & 0.309 & $67.41 \pm 11.69$ & 0.413 \\
\hline & $18.5 \sim 23.9$ & $70.92 \pm 12.28$ & & $72.19 \pm 11.34$ & 1.543 & $69.79 \pm 12.88$ & & $65.32 \pm 11.63$ & \\
\hline & $24 \sim 27.9$ & $71.77 \pm 12.75$ & & $66.12 \pm 13.27$ & & $68.79 \pm 12.70$ & & $66.67 \pm 11.21$ & \\
\hline & $\geq 28$ & $69.19 \pm 13.25$ & & $67.31 \pm 16.60$ & & $67.42 \pm 9.13$ & & $67.71 \pm 10.52$ & \\
\hline \multirow[t]{2}{*}{ Marital status } & Married & $71.46 \pm 12.35$ & 1.910 & $69.59 \pm 13.37$ & & $69.08 \pm 12.29$ & 0.184 & $66.65 \pm 11.01$ & $12.895^{\square}$ \\
\hline & Single & $62.85 \pm 9.17$ & & - & & $66.03 \pm 6.18$ & & $52.34 \pm 12.37$ & \\
\hline \multirow{3}{*}{$\begin{array}{l}\text { Educational } \\
\text { status }\end{array}$} & Illiteracy & $65.46 \pm 11.45$ & $6.542^{\boxplus}$ & $65.81 \pm 12.23$ & 0.538 & $70.43 \pm 10.88$ & 0.634 & $64.05 \pm 10.91$ & $3.099^{\square}$ \\
\hline & $\begin{array}{l}\text { Primary and } \\
\text { junior } \\
\text { secondary }\end{array}$ & $72.68 \pm 12.58$ & & $70.33 \pm 12.50$ & & $68.03 \pm 13.16$ & & $65.75 \pm 11.03$ & \\
\hline & $\begin{array}{l}\text { Senior high } \\
\text { school and } \\
\text { above }\end{array}$ & $73.85 \pm 11.78$ & & $72.22 \pm 16.26$ & & $69.87 \pm 11.35$ & & $69.17 \pm 12.02$ & \\
\hline \multirow{2}{*}{$\begin{array}{l}\text { Dwelling } \\
\text { status }\end{array}$} & Live alone & $69.25 \pm 17.61$ & 0.182 & $70.15 \pm 12.35$ & 0.139 & $67.75 \pm 12.28$ & 2.122 & $65.90 \pm 13.86$ & 0.012 \\
\hline & Others & $71.32 \pm 12.06$ & & $68.16 \pm 16.43$ & & $72.65 \pm 10.89$ & & $66.15 \pm 10.95$ & \\
\hline \multirow[t]{3}{*}{ Sleep quality } & Good & $69.21 \pm 9.02$ & 1.225 & $73.08 \pm 24.47$ & 0.136 & $69.15 \pm 13.16$ & 0.066 & $71.75 \pm 12.63$ & $13.906^{\circ}$ \\
\hline & Average & $72.89 \pm 12.64$ & & $69.96 \pm 12.05$ & & $69.08 \pm 11.88$ & & $68.73 \pm 10.66$ & \\
\hline & Poor & $69.62 \pm 12.18$ & & $67.95 \pm 15.77$ & & $67.79 \pm 8.84$ & & $61.78 \pm 10.25$ & \\
\hline \multirow[t]{2}{*}{ Payment } & Insurance & $71.94 \pm 12.64$ & 3.099 & $69.14 \pm 14.94$ & 0.077 & $69.38 \pm 12.15$ & 0.747 & $65.92 \pm 10.84$ & 0.144 \\
\hline & Self-paying & $66.80 \pm 10.07$ & & $70.58 \pm 9.68$ & & $67.16 \pm 12.58$ & & $66.55 \pm 12.45$ & \\
\hline \multirow[t]{4}{*}{$\begin{array}{l}\text { Severity of } \\
\text { symptoms }\end{array}$} & Asymptomatic & $69.01 \pm 14.79$ & $25.634^{\square}$ & $64.18 \pm 11.81$ & 2.436 & $64.05 \pm 15.79$ & 1.147 & $64.27 \pm 8.87$ & 2.582 \\
\hline & Mild & $91.77 \pm 12.78$ & & $69.64 \pm 12.33$ & & $68.79 \pm 12.35$ & & $65.39 \pm 11.26$ & \\
\hline & Moderate & $75.24 \pm 13.59$ & & $78.12 \pm 13.20$ & & $70.92 \pm 10.32$ & & $68.84 \pm 12.09$ & \\
\hline & Severe & $65.28 \pm 8.10$ & & $56.73 \pm 14.96$ & & $71.54 \pm 12.86$ & & $60.77 \pm 9.05$ & \\
\hline \multirow[t]{3}{*}{ Type of AF } & Paroxymal & $72.13 \pm 12.39$ & 0.740 & $67.38 \pm 13.20$ & 5.401 & $68.92 \pm 13.32$ & 0.366 & $67.74 \pm 10.74$ & $6.954^{\square 0}$ \\
\hline & Persistent & $69.35 \pm 12.37$ & & $81.54 \pm 16.96$ & & $69.81 \pm 10.44$ & & $62.78 \pm 12.20$ & \\
\hline & Permanency & $71.94 \pm 12.10$ & & - & & $66.51 \pm 9.04$ & & $56.77 \pm 8.75$ & \\
\hline Comorbidities & 0 & $71.10 \pm 13.89$ & 2.544 & $70.73 \pm 14.73$ & 0.861 & $75.40 \pm 8.35$ & $3.054^{\square}$ & $69.79 \pm 10.41$ & 2.955 \\
\hline
\end{tabular}

Page $11 / 13$ 


\begin{tabular}{|c|c|c|c|c|c|c|c|c|c|}
\hline & 1 & $66.86 \pm 13.95$ & & $63.73 \pm 13.20$ & & $68.47 \pm 11.47$ & & $65.04 \pm 12.83$ & \\
\hline & $\geq 2$ & $72.81 \pm 10.89$ & & $71.51 \pm 12.78$ & & $67.71 \pm 14.30$ & & $65.28 \pm 10.22$ & \\
\hline \multirow{3}{*}{$\begin{array}{l}\text { Current drug } \\
\text { types }\end{array}$} & 0 & - & & - & & - & & $62.61 \pm 10.54$ & 2.194 \\
\hline & $1-4$ & $71.62 \pm 13.13$ & 0.612 & $70.51 \pm 14.03$ & 0.283 & $69.17 \pm 17.61$ & 0.083 & $66.92 \pm 11.68$ & \\
\hline & $\geq 5$ & $69.55 \pm 8.34$ & & $67.83 \pm 12.46$ & & $68.52 \pm 10.79$ & & $66.02 \pm 8.50$ & \\
\hline \multirow{3}{*}{$\begin{array}{l}\mathrm{CHA}_{2} \mathrm{DS}_{2}^{-} \\
\text {VASC score }\end{array}$} & 0 & $59.90 \pm 9.58$ & $3.864^{\square}$ & $51.92 \pm 8.16$ & 3.916 & $60.34 \pm 17.11$ & 2.296 & $64.73 \pm 12.49$ & 1.676 \\
\hline & 1 & $71.68 \pm 12.15$ & & $62.50 \pm 11.20$ & & $68.06 \pm 14.62$ & & $62.90 \pm 13.09$ & \\
\hline & $\geq 2$ & $73.19 \pm 12.45$ & & $72.84 \pm 12.63$ & & $69.63 \pm 11.48$ & & $66.81 \pm 10.88$ & \\
\hline \multirow{3}{*}{$\begin{array}{l}\text { Duration } \\
\text { (years) }\end{array}$} & $<1$ & $70.51 \pm 12.42$ & 0.466 & $69.23 \pm 12.76$ & 1.766 & $66.22 \pm 12.61$ & 1.274 & $64.06 \pm 8.97$ & 1.083 \\
\hline & $1-5$ & $70.43 \pm 13.05$ & & $64.68 \pm 11.80$ & & $69.99 \pm 11.63$ & & $66.05 \pm 11.52$ & \\
\hline & $\otimes 5$ & $72.60 \pm 11.41$ & & $75.38 \pm 14.61$ & & $69.61 \pm 12.50$ & & $67.09 \pm 12.15$ & \\
\hline \multirow[t]{2}{*}{ QoL } & High & $71.24 \pm 12.52$ & 0.003 & $72.55 \pm 12.54$ & 3.759 & $69.41 \pm 15.02$ & 0.024 & $66.80 \pm 10.75$ & $4.946^{\square}$ \\
\hline & Low & $71.09 \pm 11.58$ & & $63.08 \pm 13.44$ & & $68.97 \pm 11.79$ & & $61.88 \pm 14.11$ & \\
\hline \multirow{2}{*}{$\begin{array}{l}\text { Radio } \\
\text { frequency } \\
\text { ablation }\end{array}$} & Yes & $72.69 \pm 8.81$ & 0.137 & $64.18 \pm 9.02$ & 1.790 & $73.08 \pm 9.29$ & 0.449 & $66.86 \pm 9.98$ & 0.104 \\
\hline & No & $71.11 \pm 12.56$ & & $71.39 \pm 14.24$ & & $68.93 \pm 12.27$ & & $66.03 \pm 11.52$ & \\
\hline \multirow[t]{2}{*}{$\begin{array}{l}\text { Re-admission } \\
(6 \mathrm{~m})\end{array}$} & Yes & $72.39 \pm 12.95$ & 0.924 & $73.06 \pm 15.89$ & 0.718 & $69.67 \pm 11.77$ & 0.352 & $62.74 \pm 11.46$ & $9.300^{\square 0}$ \\
\hline & No & $70.33 \pm 11.85$ & & $68.43 \pm 12.59$ & & $67.77 \pm 13.34$ & & $67.70 \pm 11.00$ & \\
\hline
\end{tabular}

NVAF: non-valvular atrial fibrillation; NOAC: new oral anticoagulant; BMI: Body Mass Index; QoL: quality of life; $6 \mathrm{~m}: 6$ month; $-:$ blank; : Pख0.05,

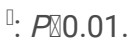

Table 4 The factors associated with the self-management in NVAF patients with different anticoagulant therapy

\begin{tabular}{|c|c|c|c|c|c|c|c|c|c|}
\hline \multirow[t]{2}{*}{ Variables } & \multicolumn{3}{|c|}{ Warfarin } & \multicolumn{3}{|c|}{ Aspirin } & \multicolumn{3}{|c|}{ No medication } \\
\hline & B & $95 \% \mathrm{Cl}$ & $P$ & B & $95 \% \mathrm{Cl}$ & $\mathrm{P}$ & $\mathrm{B}$ & $95 \% \mathrm{Cl}$ & $\mathrm{P}$ \\
\hline Gender & 3.918 & $(-0.567,8.403)$ & 0.086 & 0.400 & $(-3.253,4.054)$ & 0.829 & 1.694 & $(-1.332,4.709)$ & 0.269 \\
\hline Age & 0.603 & $(-5.823,7.029)$ & 0.459 & 8.310 & $(3.741,-12.979)$ & $\nabla 0.01^{\square[}$ & 4.651 & $(0.061,9.241)$ & 0.047 \\
\hline Educational status & 5.156 & $(1.977,8.336)$ & $\otimes 0.01^{\square \square}$ & 0.127 & $(-2.535,2.789)$ & 0.925 & 1.252 & $(-0.792,3.295)$ & 0.229 \\
\hline Comorbidities & 0.587 & $(-2.230,3.404)$ & 0.681 & -3.303 & $(-5.702,-0.842)$ & $0.015^{\square}$ & -0.978 & $(-2.946,0.989)$ & 0.328 \\
\hline $\mathrm{CHA}_{2} \mathrm{DS}_{2}$-VASC score & 2.014 & $(-3.354,7.383)$ & 0.459 & - & - & - & 0.690 & $(-3.018,4.398)$ & 0.714 \\
\hline Severity of symptom & 1.672 & $(-1.199,4.542)$ & 0.251 & - & - & - & 0.353 & $(-1.607,2.312)$ & 0.723 \\
\hline Payment & -3.375 & $(-9.453,2.702)$ & 0.274 & - & - & - & - & - & - \\
\hline Type of AF & - & - & - & - & - & - & -3.682 & $(-6.441,-0.924)$ & $\varangle 0.01^{\square}$ \\
\hline Sleep quality & - & - & - & - & - & - & -4.729 & $(-6.910,-2.548)$ & $\otimes 0.01^{\square}$ \\
\hline Married status & - & - & - & - & - & - & -10.606 & $(-18.170,-3.024)$ & $\triangle 0.01^{\square}$ \\
\hline QoL & - & - & - & - & - & - & -2.926 & $(-7.079,1.227)$ & 0.166 \\
\hline Re-admission(6m) & - & - & - & - & - & - & 1.803 & $(-1.403,5.010)$ & 0.269 \\
\hline
\end{tabular}




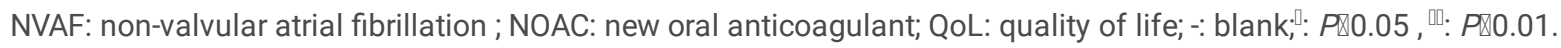

\section{Supplementary Files}

This is a list of supplementary files associated with this preprint. Click to download.

- Supplementarymaterial.docx

- Supplementarymaterial.docx 